\title{
Pilomatrixoma: A Rare Cause of Midline Neck Swelling
}

\author{
Zaka ur Rab Siddiqui \\ Department of Surgery, Al Iman General Hospital, Riyadh, Saudi Arabia
}

\begin{abstract}
Pilomatrixoma is a uncommon benign neoplasm of hair matrix origin, with usual occurrence in the head and neck region. It has bimodal age of occurrence, first peek is seen in children and the second in elderly in sixth decade. In this case, we report a case of a young boy presenting with midline neck swelling with differential diagnosis of sebaceous cyst, thyroglossal cyst or dermoid cyst. Definitive diagnosis was not made until the final histopathology report was available after complete excision. Accurate diagnosis and appropriate treatment is essential to obviate the minimal risk of recurrence or very rare malignant transformation. A high index of suspicion is required to diagnose this tumor, especially in unusual locations as in this case.
\end{abstract}

Key Words: Neck swelling, Pilomatrixoma, Histopathology.

How to cite this article: Siddiqui ZUR. Pilomatrixoma: A rare cause of midline neck swelling. J Coll Physicians Surg Pak 2019; 29(11): 1106-7.

\section{INTRODUCTION}

Pilomatrixoma, also known as pilomatricoma or calcifying epithelioma of Malherbe, is a benign neoplasm originating from protoepithelial cells or hair matrix cells, and it usually found in the subcutaneous tissue of head and neck, ${ }^{1}$ but is reported rarely elsewhere except palm, soles or genital regions. ${ }^{2-4}$ Although, in the literature, some cases are described by dermatologists and plastic surgeons, it is not very commonly encountered in clinical practice, especially in midline of neck. ${ }^{2}$ In the current article, we report a case of pilomatrixoma presenting as midline neck swelling and thus causing confusion with dermoid cyst or thyroglossal cyst. Its definitive diagnosis could only be made after histopathologic examination of the excised specimen.

\section{CASE REPORT}

A 13-year boy presented in the outpatient clinic with insidious onset, and painless swelling in the midline of the front of the neck for the past 4-5 months. The mass was slowly enlarging but there was no discharge. He denied any history of fever, chills, weight loss, trauma to the area or any previous similar complain. He had no other medical problems and no known food or drug allergies.

Physical examination revealed about $2 \times 2 \mathrm{~cm}$, midline, non-tender, firm to hard, neck mass with irregular consistency, not infiltrating the overlying skin or adherent to deep fascia, not moving with swallowing or tongue protrusion (Figure 1). The neck was supple with no other palpable masses or cervical lymphadenopathy.

Correspondence to: Dr. Zaka ur Rab Siddiqui, Consultant General and Laparoscopic Surgeon, Al Iman General Hospital, Riyadh, Saudi Arabia

E-mail:drzaka2003@yahoo.com

Received: December 03, 2018; Revised: March 20, 2019; Accepted: March 28, 2019

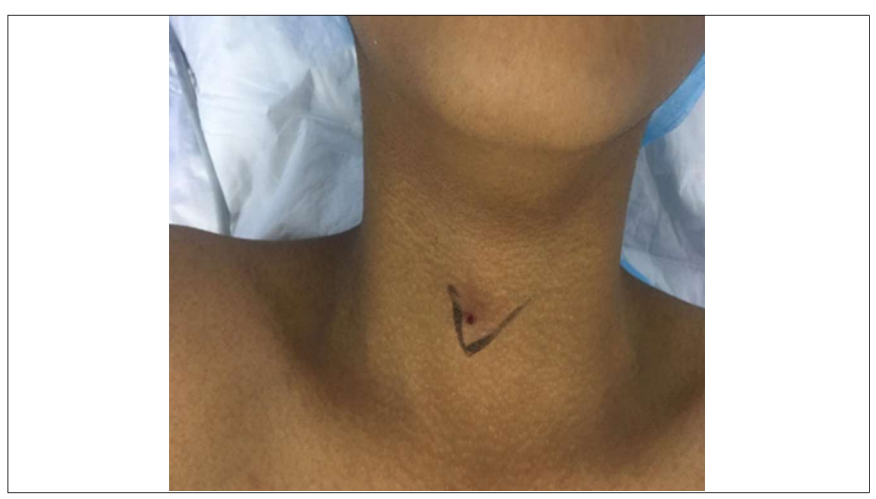

Figure 1: Clinical appearance of the swelling.

Complete blood count (CBC) showed hemoglobin of 14 $\mathrm{g} / \mathrm{dl}$ with white blood cell count of $6.7 \times 10^{3} / \mathrm{uL}$ with high lymphocyte count $(45 \%)$ and eosonophilia $(0.9 \%)$ as well as mildly elevated basophil count $(0.12 \%)$.

Computed tomography (CT) scan was done and showed small, well defined, subcutaneous, enhancing soft tissue denisty mass lesion measuring about $11 \times 14 \mathrm{~mm}$, at the front of the lower part of the neck. Multiple small, punctate calcifications were seen. The swelling was not related to the thyroid gland. CT findings were suggestive of small haemangioma with calcifications (Figure 2).

Fine needle aspiration cytology (FNAC) was performed and showed superficial anucleated squamous cells with scattered benign mature squamous cells and few small lymphocytes. No malignant cells were seen. The picture was reported consistent with epidermal cyst or a component of thyroglossal cyst.

Exicional biopsy was planned for the lesion. The mass was excised completely with around $1 \mathrm{~cm}$ margin circumferentially along with overlying skin and sent for histopathology. The final diagnosis came out to be pilomatrixoma. 


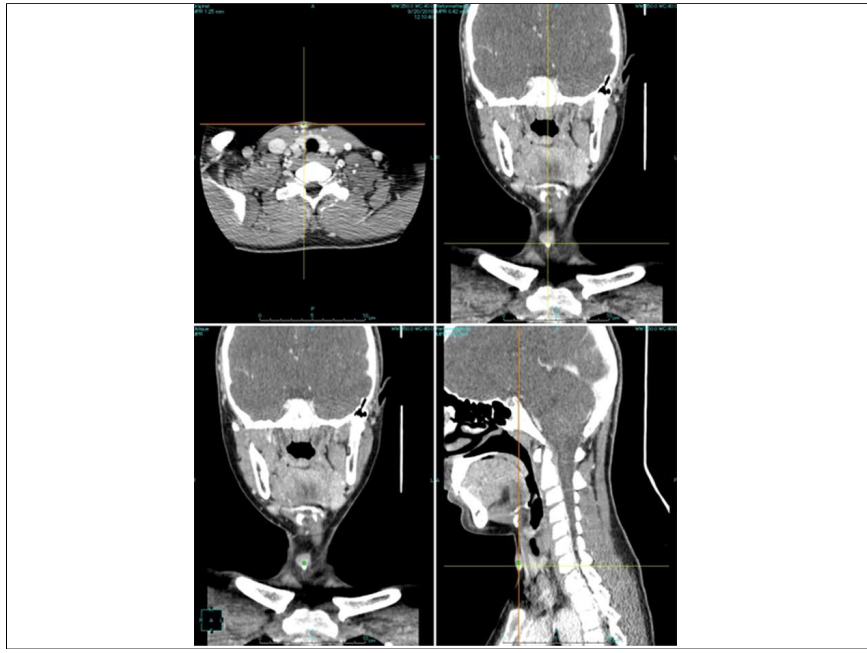

Figure 2: CT images of the neck swelling in several sections.

The patient recovered well postoperatively and showed no recurrence in the follow-up period of one year duration.

\section{DISCUSSION}

Pilomatrixoma can be defined as a hair matrix origin benign skin appendageal tumor. ${ }^{1}$ It usually occurs in the head and neck region, although cases are also reported elsewhere, especially in the upper extremities. 3,4 Although there is no age predisposition, the lesion is more common in children and teenagers (particularly in females). ${ }^{3-5} \mathrm{~A}$ second peek is described in sixth decade. 6,7

Commonly, these tumors present as a solitary nodule; however, multiple occurrences are reported in $2 \%$ to $10 \%$ of cases. ${ }^{4,8,9}$ Despite being a well-defined entity, pilomatrixomas are misdiagnosed frequently and may even not considered in the differential diagnoses, neither clinically nor during cytological reporting. ${ }^{5}$ In some case reports, it was even misdiagnosed as a malignant tumor.5,6 Usually, these tumors present as a superficial, firm, solitary, slow-growing, painless mass in the dermis. The overlying skin can be normal or may show a bluish or bluish-red discoloration (leading to misdiagnosis of hemangioma) or less frequently ulceration.6,7,8 These are characterised by calcification within the lesion, which makes them feel firm to hard, and often results in an irregular angulated shapes when stretched; this is referred as 'tent sign,' which indicates several facets and irregular angles of pilomatrixoma. On CT scan, these show noninfiltrating mass like lesions containing calcifications within the subcutaneous tissues. $6,8,9$ Although, FNAC can yield the diagnosis accurately, 5 it may be inaccurate in upto $45 \%$ cases as reported by Wang et al. ${ }^{10}$ The treatment of choice is excision with adequate margins with regular follow-up. Despite very low recurrence, it can have malignant potential, 10 so the patient should be kept under active surveillance.

To sum up, the diagnosis of pilomatrioma should be included in the differtial diagnosis of a slow-growing swelling with irregular margins in head and neck region, especially in the teenagers. Complete resection of the lesion with adequate margin is advised to eliminate the risk of recurrence and very rare transformation to malignant pilomatricoma. ${ }^{11}$

In conclusion, the diagnosis of pilomatrioma is usually incorrect. Preoperatively, a high index of suspicion during clinical examination would help making in a more accurate diagnosis. A regular follow-up is needed after excision, as on rare occasions, malignant transformation and recurrence are noted and reported.

\section{CONFLICT OF INTEREST:}

Authors declared no conflict of interest.

\section{AUTHOR'S CONTRIBUTION:}

ZURS: Contributed to the conception or design of the work; or the acquisition, analysis, or interpretation of data for the work; drafted the work or revised it critically for important intellectual content; finally approved of the version to be published; agreed to be accountable for all aspects of the work in ensuring that questions related to the accuracy or integrity of any part of the work are appropriately investigated and resolved.

\section{REFERENCES}

1. Duflo S, Nicollas R, Roman S, Magalon G, Triglia JM. Pilomatrixoma of the head and neck in children: A study of 38 cases and a review of the literature. Arch Otolaryngol Head Neck Surg 1998; 124:1239-42.

2. Yoshimura Y, Obara S, Mikami T, Matsuda S. Calcifying epithelioma (pilomatrixoma) of the head and neck: Analysis of 37 cases. Br J Oral Maxillofac Surg 1997; 35:429-32.

3. Wagner AM. A 12 years old girl with an enlarging nontender nodule on the arm. Pediatr Ann 2006; 35:445-7.

4. Lan MY, Lan MC, Ho CY, Li WY, Lin CZ. Pilomatricoma of the head and neck: A retrospective review of 179 cases. Arch Otolaryngol Head Neck Surg 2003; 129:1327-30.

5. Kumaran N, Azmy A, Carachi R, Raine PA, Macfarlane JH, Howatson AG. Pilomatrixoma-accuracy of clinical diagnosis. J Pediatr Surg 2006; 41:1755-8.

6. Som PM, Shugar JMA, Silvers AR. CT of pilomatrixoma in the cheek. Am J Neuroradiol 1998; 19:1219-20.

7. Malherbe A, Chenantais J. Note sur lepith elioma calcify edes glandes sebacees. Progressi Medicina 1880; 8:826-37.

8. Julian CG, Bowers PW. A clinical review of 209 pilomatricomas. J Am Acad Dermatol 1998; 39:191-5.

9. Agarwal RP, Handler SD, Matthews MR, Carpentieri D. Pilomatrixoma of the head and neck in children. Otolaryngol Head Neck Surg 2001; 125:510-5.

10. Wang J, Cobb CJ, Martin SE, Venegas R, Wu N, Greaves TS. Pilomatrixoma: Clinicopathologic study of 51 cases with emphasis on cytologic features. Diagn Cytopathol 2002; 27:167-72.

11. Niedermeyer HP, Peris K, Hofler H. Pilomatrix carcinoma with multiple visceral metastases: Report of a case. Cancer 1996; 77:1311-4.

$$
\text { …ㄷ….. }
$$

